\title{
A gestão eletrônica de documentos (GED) em uma cooperativa de prestação Assistencial à saúde: um estudo de caso
}

\author{
The electronic document management (EDM) in the provision of cooperative assistance to \\ health: a case study
}

\begin{abstract}
Resumo
Atualmente, as cooperativas estão utilizando a Gestão Eletrônica de Documentos (GED) em seus arquivos objetivando a alta velocidade e a agilidade na localização dos documentos. Nesse sentido, este trabalho tem como objetivo identificar e compreender o funcionamento da GED, segundo os modelos de Ágora (2012) e Silva (2003), em uma cooperativa. Este estudo caracteriza-se com uma pesquisa qualitativa, de caráter descritivo, com ênfase em um estudo de caso, sendo realizadas entrevistas, bem como observação direta e análise documental. Os resultados revelaram a importância da GED para minimizar a troca de documentos entre a matriz e suas filiadas. Evidenciouse também o pouco conhecimento do grupo entrevistado sobre os referenciais teóricos que apresentam as etapas da GED. Ficou evidente através dos relatos, a correlação e coerência entre as etapas descritas por Ágora (2012) e Silva (2003) e as etapas aplicadas pela Unimed Central RS.
\end{abstract}

Palavras-chave: Gestão eletrônica de documentos; Cooperativas; Unimed Santa Maria.

\begin{abstract}
Currently, cooperatives are using the Electronic Document Management (EDM) in your files aimed at high speed and agility on the location of the documents. In this sense, this work aims to identify and understand the functioning of the GED, according to the models of Agora (2012) and Silva (2003), in a cooperative. This study is characterized by a qualitative research, descriptive, focusing on a case study, interviews being conducted, as well as direct observation and document analysis. The results revealed the importance of GED to minimize the exchange of documents between the matrix and its affiliates. It also showed the little knowledge of the group interviewed about the theoretical frameworks that present the steps of the GED. It was evident from the reports, correlation and consistency between the steps by Agora (2012) and Silva (2003) and the steps implemented by the Unimed Central $R S$.
\end{abstract}

Keywords: Electronic document management; Cooperatives; Unimed Santa Maria.

Recebido: 14/09/2016 Aceito: 16/12/2016

Julio Cezar Lucion Farinha ${ }^{1}$, Gustavo Fontinelli Rossés ${ }^{2}$, Débora da Luz Fernandes ${ }^{3}$ e Carla Rosane da Costa Sccott ${ }^{4}$

${ }^{1}$ Universidade Federal de Santa Maria, Graduação em Gestão de Cooperativas - julio-lucion@ hotmail.com - Rua Três Barras, 1205, Distrito Arroio Grande, Santa Maria - RS, CEP 97120-000

${ }^{2}$ Universidade Federal de Santa Maria, Doutorado em Extensão Rural - gustavo@politecnico.ufsm.br

${ }^{3}$ Universidade Federal de Santa Maria, Graduação em Fisioterapia - deboradaluzfernandes @ yahoo.com.br

${ }^{4}$ Instituto Federal Farroupilha, Mestra em Engenharia de Produção - carla.sccott@iffarroupilha.edu.br 


\section{Introdução}

A base filosófica do cooperativismo foi resultante de várias experiências ao longo dos anos, conforme afirma a OCB Organização das Cooperativas do Brasil (OCB, 2004). No século XIX, no auge da Revolução Industrial, surgiu a primeira cooperativa, com o objetivo de gerar um modelo econômico mais justo e participativo (HOLYOLAKE, 1989).

O Cooperativismo é a doutrina que preconiza a colaboração e a associação de pessoas ou grupos com os mesmos interesses, a fim de obter vantagens comuns em suas atividades econômicas seguindo os sete princípios, que são as linhas orientadoras por meio das quais as cooperativas levam os seus valores à prática (OCB, 2008).

$\mathrm{O}$ Cooperativismo se fortalece em resposta às dificuldades socioeconômicas, como um fator de inclusão social e como uma alternativa para que muitos se mantenham no mercado de trabalho.

Os novos modos de gestão vêm se tornando um impulso para que os conceitos de participação nas tomadas de decisão e na estruturação de estratégias organizacionais que favorecem o diferencial competitivo das cooperativas sejam revistos.

Preconiza-se, segundo Mendes e Passador (2010), que o cooperado esteja presente, dê seu voto de confiança e participe com visão e ação, possibilitando o passo fundamental para a solução de problemas e a elaboração de novos projetos em busca de qualidade. Ressalta-se ser importante que a participação aconteça de forma organizada, comprometida e com responsabilidade. Espera-se, assim, que os cooperados assumam o papel de verdadeiros donos e conheçam o objetivo da cooperativa.

Nesse contexto, acredita Carvalho (2010), que os gestores das cooperativas e os cooperados vêm repensando o conceito de participação nas tomadas de decisão e na reestruturação de sua forma de organização. Ademais, são amplamente notórios os desafios e dificuldades encontrados nas organizações cooperativas. Em um estudo realizado por Santos e Roquete (2013) sobre as práticas de gestão em cooperativas, eles concluíram sobre a necessidade de haver mudanças nas bases culturais, nos valores, nos princípios e nas crenças. Percebeu-se que não há troca de informações entre os cooperados e que a comunicação é falha, tanto por parte da cooperativa com os cooperados, quanto vice-versa, e isto é devido à cultura da organização.

Dentre as causas que dificultam a permanências das cooperativas no mercado se destacam os problemas de gestão, dificuldade de capitalização e limitação de atuação da cooperativa advindos de seus próprios princípios e particularidades. As cooperativas têm que lidar com demandas específicas dos sócios, com o conflito de papeis dos membros além de outros problemas inerentes a sua forma de organização (MENDES e PASSADOR, 2010).

Atualmente, nas cooperativas, um dos sete princípios valiosos da doutrina cooperativista é a informação. É raro o processo ou a atividade que não as produzam e estas precisam ser organizadas, armazenadas e disponibilizadas.

A organização precisa fazer uso da informação, sabendo identificá-la para usufruir de maneira adequada. Já alertava Beal (2009) que a informação é um patrimônio, ela agrega valor à organização. Não se trata de inúmeros bytes aglomerados, mas sim de um conjunto de dados classificados e organizados de forma que uma pessoa ou uma cooperativa possa tirar proveito. A informação é inclusive um fator que pode determinar a sobrevivência ou a descontinuidade das atividades de um negócio. E isso não é difícil de ser entendido. Basta imaginar o que aconteceria se uma instituição perdesse todas as informações de seus clientes.

Apesar de possível, muito dificilmente uma empresa de grande porte consegue perder suas informações, principalmente quando se fala de bancos, cadeias de lojas, entre outros.

No entanto, o que ocorre com mais frequência é o uso inadequado das informações adquiridas ou, ainda, a subutilização destas. É nesse ponto que a Tecnologia da Informação pode ajudar (ALECRIM, 2011).

Atualmente, com o avanço tecnológico, as cooperativas, tentando se adequar as novas realidades estão se valendo do uso da tecnologia da informação em suas estratégias. Buscando rever esse ponto da estruturação das informações que está em constante transformação e querendo alta velocidade e agilidade na localização dos documentos, algumas cooperativas vêm fazendo a gestão de documentos em seus arquivos e implantando uma solução tecnológica chamada de Gestão Eletrônica de Documentos (LIMA, 2013). 
A Gestão Eletrônica de Documentos (GED) é uma tecnologia que provê um meio de facilmente gerar, controlar, armazenar, compartilhar e recuperar informações existentes em documentos. Os sistemas GED permitem aos usuários acessarem os documentos de forma ágil e segura (MORENO, 2008).

Com a GED é possível realizar a digitalização de documentos, permitindo a preservação da documentação, a agilidade no gerenciamento e no fluxo de documentos e o aumento da velocidade na troca de informações tornando os processos de negócios mais rápidos (SANTOS, 2005).

O mesmo autor reforça que a GED é uma ferramenta de trabalho que traz novas vantagens para a dinâmica das cooperativas como: agilidade na distribuição, na localização e na apresentação de documentos; preservação do acervo documental, evitando extravio de documentos e conferindo segurança aos processos; maior controle do processo de negócio, facilitando o rastreamento e a identificação de possíveis gargalos; aumento do controle no cumprimento de prazos e normas internas e de órgãos reguladores.

Diante de tais considerações, este trabalho tem como objetivo identificar e compreender $o$ funcionamento da gestão eletrônica de documentos (GED) em uma cooperativa do ramo da saúde, da região Central do Rio Grande do Sul.

Sendo assim, esse trabalho justifica-se por apresentar um tema de grande interesse para as Cooperativas, pois todas passam por este processo de inovação tecnológica. Por isso a importância de buscar sempre incentivar as organizações a implementar novas técnicas como a GED, que agrega inúmeras vantagens com excelente relação custo/benefício, agilidade e eficiência.

As cooperativas vêm colocando em prática esse tipo de solução, principalmente entre aquelas que têm filiadas, para conseguir, por exemplo, minimizar a troca de documentos via malotes ou similares entre a matriz e suas filiadas, trazendo assim melhorias nos processos operacionais, ganhando economia de espaço físico e até ainda oportunizando redução de custos com impressões (LIMA, 2013).

Além disso, um estudo desta natureza é relevante por ser diferenciado e por propiciar a ampliação de conhecimentos no que tange à gestão eletrônica de documentos e suas funcionalidades nas cooperativas, pela dimensão a ser estudada e pela disseminação dos resultados a serem gerados aos participantes.

Para dar o entendimento apropriado a este trabalho, no Capítulo 2 será exposta uma revisão da literatura discutindo os conceitos básicos sobre as organizações cooperativas, seus princípios e tipos, bem como sobre a Gestão Eletrônica de Documentos, seus conceitos, objetivos, importância e suas características principais. A seguir, no Capítulo 3, serão apresentados os procedimentos metodológicos que foram utilizados no desenvolvimento deste trabalho. Já no Capítulo 4, apresentam-se os resultados para identificar a organização estudada como modelo de investigação, fundamentais para se entender a gestão eletrônica de documentos, bem como a compressão do efeito da GED nas rotinas organizacionais. E por fim, no Capítulo 5 são apresentadas as considerações finais a respeito do trabalho.

\section{Referencial Teórico}

\subsection{Cooperativismo}

O cooperativismo teve seu início em 1844 na época da revolução industrial na Inglaterra, quando 28 tecelões uniram-se e fundaram a primeira cooperativa de consumo. Esses tecelões, chamados "Pioneiros de Rochdale" preocupados com escassez de recursos e dificuldades dos trabalhadores após a crise da revolução industrial, uniram-se em favor dos menos favorecidos, pois tinham por vontade a cooperação e ajuda mútua (HOLYOAKE, 1993).

No Brasil, a primeira cooperativa nasceu em 1889, na cidade de Ouro Preto, Minas Gerais. No Rio Grande do Sul, na cidade de Nova Petrópolis, através do padre Theodor Amstadt, em 1902, foi fundada a primeira cooperativa de crédito. As demais cooperativas tiveram seu início a partir de 1906, por iniciativa dos imigrantes alemães e italianos, que trouxeram suas experiências, organizando-se através das cooperativas (OCB, 2014).

O Cooperativismo é um movimento, filosofia de vida e modelo socioeconômico capaz de unir desenvolvimento econômico e bem-estar social. Seus referenciais fundamentais são: participação democrática, solidariedade, independência e autonomia (OCB, 2008).

Fortalecido em conceitos de humanismo, liberdade, igualdade, solidariedade e de racionalidade, 
o cooperativismo busca construir uma sociedade melhor, baseada em conceitos nobres, destacando-se cada vez mais como uma opção e uma solução para o crescimento da economia em tempos difíceis (SANTOS e CEBALLOS, 2006).

São sete os princípios do Cooperativismo segundo a OCB: adesão livre e voluntária; gestão democrática; participação econômica dos sócios; autonomia e independência; educação, formação e informação; intercooperação; e interesse pela comunidade.

Atualmente existem cooperativas brasileiras em 13 ramos da economia: consumo, social, trabalho, educacional, transporte, agropecuária, ramo da saúde, crédito, habitacional, produção, infraestrutura, mineral, turismo e lazer (OCB, 2014).

Dessa forma, o cooperativismo é um movimento que se fortalece no mundo todo por promover $\mathrm{o}$ desenvolvimento econômico sustentável e inclusivo, gerando $\mathrm{o}$ bem-estar social dos indivíduos $\mathrm{e}$ comunidades onde está presente.

A importância da cooperação vem desde os primórdios da história da humanidade, quando os homens precisavam se unir para enfrentar as adversidades naturais, as condições climáticas e lutar por sua sobrevivência e de suas comunidades.

A cooperação se evidencia como mola propulsora da evolução do mundo e das pessoas $\mathrm{O}$ setor cooperativo está presente nos cinco continentes, reúne 1 bilhão de pessoas em mais de 100 países e gera mais de 100 milhões de empregos (MENEZES, 2012).

Considerando a importância e a influência do sistema cooperativista à sociedade e à economia brasileira, torna-se de grande relevância a realização de estudos sobre esse setor buscando incentivar um mundo cada vez mais cooperativo.

\subsection{Gestão eletrônica de documentos (GED)}

Fortes tendências e fatores tecnológicos estão direcionando mudanças na estratégia das cooperativas. Os mais marcantes, segundo Bettis e Hitt (1995), são a taxa crescente da mudança e inovação tecnológica, e a chamada "era da informação". Essa mudança tecnológica, segundo Schendel (1995), tem forte impacto psicológico e sociológico, e obriga as cooperativas a pensar novas maneiras de gerenciamento, com novos padrões de eficiência e produtividade. Isso está sendo amplamente visível na gestão e arquivamento de documentos.

Tapscott (1995) discute o nascimento de nova era, em construção, de nova economia, nova política, nova organização e novos indivíduos, com ajuda da tecnologia da informação (TI), transformando a economia em processos digitais e inteligência em rede.

Para Campos Filho (1994), a TI é o conjunto de hardware e software que desempenha uma ou mais tarefas de processamento de informações. Faz parte do sistema de informação das organizações, tal como coletar, transmitir, estocar, recuperar, manipular e exibir dados. Aí podem estar incluídos microcomputadores (em rede ou não), mainframes, scanners de código de barra, estações de trabalho, software de planilhas eletrônicas ou banco de dados, entre outros.

Em se tratando de novas tecnologias da informação, é notória, atualmente a utilização da Gestão Eletrônica de Documentos (GED) a qual visa à estruturação de documentos com padrões prédefinidos, a alta velocidade e a agilidade na localização dos documentos digitalizados. Esse sistema operacional possibilita a apresentação de respostas precisas e instantâneas, a automação dos processos, a disponibilidade e a acessibilidade de contratos pelo usuário direto no sistema de armazenamento e a economia de papéis visto que os contratos e contas são disponibilizados via eletrônica e são armazenados em bancos de dados (GEDNET, 2016).

No Brasil, a gestão de documentos institucionalizou-se com a aprovação da Lei n. 8.159, de 08 de janeiro de 1991, que em seu artigo $3^{\circ}$, define gestão documental como sendo "[...] o conjunto de procedimentos e operações técnicas à sua produção, tramitação, uso, avaliação e arquivamento em fase corrente e intermediária, visando à sua eliminação ou recolhimento para guarda permanente" (BRASIL, 1991).

Ademais, Tiago e Reis (2011, p. 110), afirmam que "[...] GED é um conjunto de procedimentos informatizados com a finalidade de otimizar e racionalizar a gestão documental".

Em linhas gerais, pode-se descrever a GED como um conjunto de tecnologias que permite a uma empresa gerenciar seus documentos em forma digital. Esses documentos podem ser das mais diversas origens, tais como papel, microfilme, imagem, som, 
planilhas eletrônicas, arquivos de texto, entre outros (GEDNET, 2016).

No entendimento de Gednet (2016), as principais tecnologias relacionadas à GED são:

- Capture: acelera processos de negócio através da captação de documentos e formulários, transformando em informações confiáveis e recuperáveis, passíveis de serem integradas a todas as aplicações de negócios.

- Document Imaging (DI): é a tecnologia de GED que propicia a conversão de documentos do meio físico para o digital. Trata-se da tecnologia mais difundida da GED, muito utilizada para conversão de papel em imagem, através de processo de digitalização com aparelhos scanners.

- Document Management (DM): é a tecnologia que permite gerenciar com mais eficácia a criação, revisão, aprovação e descarte de documentos eletrônicos. Dentre as suas principais funcionalidades estão o controle de informações (autoria, revisão, versão, datas etc.), segurança, busca, check-in/checkout e versionamento.

- Workflow/BPM: controla e gerencia processos dentro de uma organização, garantindo que as tarefas sejam executadas pelas pessoas corretas no tempo previamente definido.

Organiza tarefas, prazos, trâmites, documentos e sincroniza a ação das pessoas.

- COLD/ERM: tecnologia que trata páginas de relatórios, incluindo a captura, indexação, armazenamento, gerenciamento e recuperação de dados. Esta tecnologia permite que relatórios sejam armazenados de forma otimizada, em meios de baixo custo, mantendo-se sua forma original.

- Forms Processing: tecnologia que possibilita reconhecer as informações e relacioná-las com campos em bancos de dados, automatizando o processo de digitação. Neste sistema são utilizados o ICR (Intelligent Character Recognition) e OCR (Optical Character Recognition) para o reconhecimento automático de caracteres.

- Records and Information Management (RIM): é o gerenciamento do ciclo de vida de um documento, independente da mídia em que se encontre. Através de um sistema RIM gerencia-se a criação, armazenamento, processamento, manutenção, disponibilização e descarte dos documentos, sob controle de categorização e tabelas de temporalidade.

É importante enfatizar as vantagens e desvantagens da GED. Em se tratando dos benefícios com a implantação do mesmo, é possível citar as seguintes vantagens: facilidades referentes à recuperação, ao acesso, à organização, preservação e ao controle do universo documental/informacional, otimização das atividades; agilidade no processo de disseminação e no acesso à informação; maior confiabilidade e eficiência; redução de áreas de arquivamento; redução no tempo de recuperação da informação; rapidez para atualização dos dados; acesso múltiplo e simultâneo em rede da informação; cópias de segurança; diminuição da circulação do volume documental no suporte físico; preservação dos originais; redução de custos com cópias; aumento da capacidade e qualidade de armazenagem em microfilme e controle da informação (ÁGORA, 2012).

No entendimento de Werlich (2007) a GED ainda possui outras vantagens como: compartilhamento dos documentos, acabando com a necessidade de criação de várias cópias do documento; armazenamento centralizado em local específico (servidor), agilizando o acesso e possibilitando seu controle; automatização de processos, possibilitando maior produtividade; e redução de espaço físico para armazenamento de documentos em papel.

Já, alguns aspectos analisados são concludentes no que diz respeito às desvantagens que o sistema apresenta, destacando, dentre eles: constantes mudanças de mídia, aspectos legais dos documentos digitais, recursos tecnológicos se tornam rapidamente obsoletos, e obrigatoriedade da existência de equipamento e software para a recuperação do dado (ÁGORA, 2012).

De acordo com Baldam et al. (2002), podem ocorrer problemas na implantação da GED. Para Starbird e Vilhauer (1997, p. 88), a GED, se "mal planejado, pode nunca chegar a funcionar da forma pretendida ou imaginada".

Conforme Ágora (2012) e Silva (2003) o procedimento operacional padrão ou processo de digitalização da GED, de forma sucinta, ocorre na seguinte sequência, apresentada na figura 1, a seguir.

Figura 1: Procedimento operacional da GED

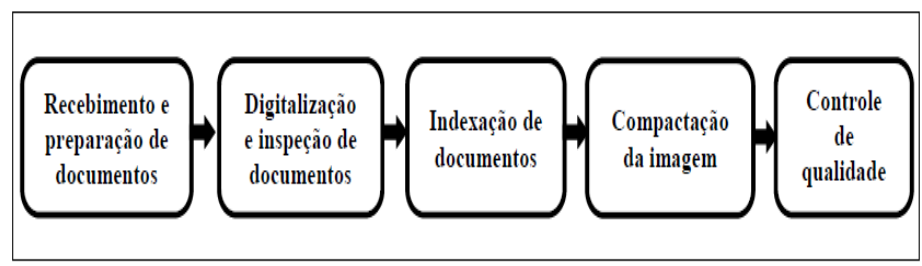

Fonte: adaptado Ágora (2012); Silva (2003). 
a) Recebimento e preparação do documento: uma equipe treinada pode realizar esta atividade ou mesmo um birô, devendo ocorrer antes da digitalização do documento. O procedimento deverá ser feito em cada documento, removendo manualmente grampos, clipes e fitas gomadas, como também o conserto de páginas rasgadas.

b) Digitalização e inspeção de documentos: os documentos são pré-classificados em lotes, e o escâner é ajustado conforme a documentação a ser digitalizada, levando-se em conta o tamanho e a cor do documento. Logo após a digitalização, as imagens dos documentos são inspecionadas, evitando imagens ilegíveis. Caso contrário, o documento pode ser digitalizado novamente.

c) Indexação de documentos: a indexação depende de um índice preciso para que os documentos possam ser localizados, selecionados e recuperados para visualização ou cópia. Este índice pode ser por assunto, data, número e nome.

d) Compactação da imagem: a compactação reduz o tamanho da imagem digitalizada para armazenamento e transmissão, e é realizada controlando a resolução da imagem digitalizada.

e) Controle de qualidade: exame cuidadoso e sistemático é realizado em cada lote convertido, verificando a qualidade das imagens e a indexação.

No entendimento de Baldam et al., (2002) o ambienta típico da GED apresenta uma variedade de configurações de acordo com o desejo de aplicação. A figura 2, a seguir, mostra um sistema com componentes típicos.

\section{Figura 2: Ambiente típico de GED}

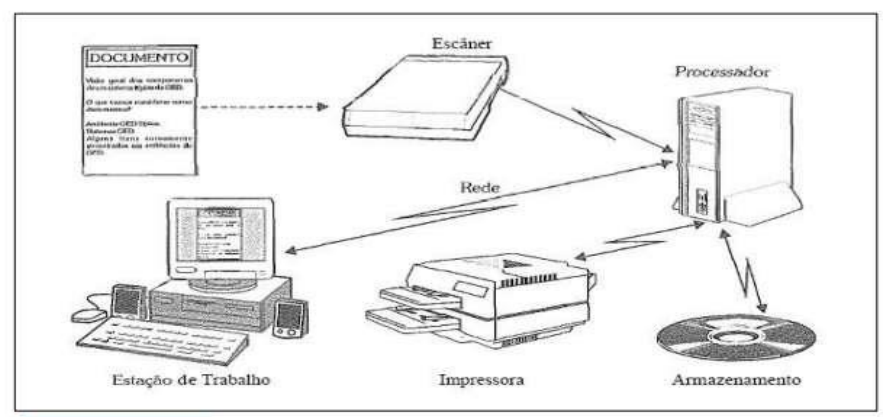

Fonte: Baldam et al. (2002)

a) Documentos: em papel ou originalmente digital.

b) Scanner: instrumento utilizado para digitalizar o documento, ou seja, obter uma imagem do documento e ser armazenada eletronicamente. c) Processador: é normal os sistemas GED serem instalados em um ou mais computadores, em rede, para facilitar a distribuição de informação.

d) Armazenamento: em um servidor próprio de imagens ou outro ambiente computacional.

e) Impressora: equipamento usado quando há a necessidade de obter uma cópia física do documento.

f) Estação de trabalho: computador para acesso ao servidor que pode permitir consultar, criar novos documentos, cadastrar documentos existentes, entre outros.

Com base nestes elementos teóricos, assumiu-se neste trabalho, o desafio de confrontar os aspectos destacados por Ágora (2012), Silva (2003) e Baldam et al. (2002) com as práticas desenvolvidas na Cooperativa a ser estudada.

Entendeu-se que estes elementos teóricos foram considerados essenciais e suficientes para servir de suporte para a construção das categorias de análise, bem como necessários para atender aos objetivos da pesquisa.

\section{Metodologia}

\subsection{Caracterização da pesquisa e abordagem}

Para atender aos objetivos e finalidades deste trabalho, foi utilizada a abordagem qualitativa, que faz o uso de linguagem em forma de texto para descrição e interpretação da pesquisa na compressão e análise de dos dados.

As pesquisas qualitativas envolvem a observação intensiva e de longo tempo em um ambiente natural, o registro preciso e detalhado do que acontece no ambiente e a interpretação e a análise de dados utilizando descrições e narrativas.

Assim, percebe-se que as pesquisas qualitativas tentam descrever um fato ou um objeto, sem usar de métodos estatísticos. São desenvolvidas por meio da observação, onde o pesquisador tenta entender o fenômeno estudado pela perspectiva dos agentes envolvidos no processo, para, a partir daí, definir sua interpretação e descrição dos fatos (GOLDENBERG, 2007).

\subsection{Procedimentos}

Esta pesquisa é descritiva, por apresentar características de determinada população ou fenômeno, ou ainda, estabelece relações entre as 
variáveis. Esta abordagem foi considerada mais adequada neste estudo, pois segundo Lakatos e Marconi (2001) neste tipo de pesquisa os fatos são observados, registrados, analisados, classificados e interpretados, sem interferência do pesquisador.

Quanto ao procedimento técnico, a pesquisa apresenta características de um estudo de caso, o qual, segundo Gil (1996), é caracterizado pelo estudo profundo e exaustivo de um ou de poucos objetos, de maneira que permita o seu amplo e detalhado conhecimento.

Para Stake (2000), o estudo de caso como estratégia de pesquisa, caracteriza-se justamente por esse interesse em casos individuais e não pelos métodos de investigação, os quais podem ser os mais variados, tanto qualitativos como quantitativos. Mas, o autor alerta para o fato de que "nem tudo pode ser considerado um caso" e oferece algumas pistas para a identificação do que pode constituir um caso. Para ele, um caso é uma unidade específica, um sistema delimitado cujas partes são integradas.

Sendo assim, neste estudo tomou-se como caso de análise a Cooperativa de Assistência à Saúde Ltda, mais conhecida como Unimed, unidade de Santa Maria. Esta organização apresenta uma propriedade coletiva e democraticamente gerida. E ainda, essa sociedade cooperativa é uma associação autônoma de pessoas que se unem voluntariamente, para satisfazer aspirações e necessidades econômicas, sociais e culturais comuns ao povo da Região Central do Estado.

Dessa forma, foi realizada uma observação do funcionamento da gestão eletrônica de documentos durante o período dedicado ao estágio, procurando relacionar os conceitos formulados à sua aplicação na prática, participando do dia a dia da organização, bem como desempenhando funções, o que possibilitou uma maior interação do aluno pesquisador com o cotidiano da referida cooperativa.

\subsection{Técnicas}

Para que este trabalho pudesse ser realizado com o propósito desejado, utilizou-se como forma de obter as informações, a análise documental, a observação direta e as entrevistas. Minayo (2004) reforça que essas técnicas são importantes ao processo de coleta de dados e auxiliam o pesquisador a ter acesso às possíveis respostas que se deseja obter ao longo do processo de investigação.
A análise documental tem como propósito extrair um reflexo objetivo da fonte original, permitindo a localização, identificação, organização e avaliação das informações contidas no documento, além da contextualização dos fatos em determinados momentos, conceitos esses suplantados por Moreira (2005).

A saber, foram acessados os seguintes documentos: Manual do Procedimento Operacional Padrão da Gestão Eletrônica de Documentos, conhecido como POP, e Sistema de Captura de Documentos para o Intercâmbio Nacional Unimed popularmente conhecido como SICADIN. O POP foi elaborado em 2014 pelos funcionários que atuam diretamente com a ferramenta de trabalho estudada e foi aprovado pelo Conselho Administrativo da Cooperativa Unimed Santa Maria para a sua posterior utilização. Já o SICADIM foi criado na Central de Serviços, Unimed, Rio Grande do Sul.

A observação direta teve como finalidade permitir a constatação, na prática, de algumas impressões obtidas pelas entrevistas e análises documentais realizadas. Segundo Quivy e Camenhoudt (2005), a observação direta apresenta o objetivo de captar os comportamentos no momento em que os mesmos se produzem e em si mesmos, sem a mediação de documentos ou testemunhos posteriores.

A observação direta, neste estudo, foi efetivada por meio da observação dos funcionários que operam diretamente o Programa Operacional Padrão de Gestão Eletrônica de Documentos. Dessa forma foi observado desde o recebimento e a preparação de documentos, a confecção de capas de lote, o destaque e ordenação de contratos, a disponibilização de préexistências, a confecção de etiquetas autoadesivas, a organização e preparação de contratos para armazenamento, a montagem e remontagem de contas, a separação de obrigatório e não obrigatório, o tratamento e indexação de documentos, o atendimento as demandas internas e externas, a procura de documentos na plataforma de armazenamento da Central RS, a organização do acervo de documentos no sistema arquivístico, o fechamento de faturas e manutenção da envelopadora, a digitalização, o procedimento de etiquetamento e, enfim, o armazenamento de contratos.

Em se tratando das entrevistas, estas foram construídas com base em um conjunto de categorias de análise delineadas a partir das temáticas expostas no referencial teórico deste estudo. Tais entrevistas 
foram feitas com diferentes profissionais com atuação direta e significativa na respectiva organização investigada. Sendo assim, as entrevistas foram realizadas com 05 (cinco) profissionais que atuam no setor de faturamento da Cooperativa e que exercem os seguintes cargos: três auxiliares administrativos, um analista da GED e um gerente geral.

Com base nestas técnicas de coleta, buscou-se conhecer as ações e os procedimentos realizados pela Cooperativa estudada, no que se refere à gestão eletrônica de documentos, objetivo deste estudo.

Assim, entendeu-se ter condições de promover a análise das informações obtidas. Conforme Lakatos e Marconi (2001), a análise dos resultados tem como objetivo principal permitir ao pesquisador $\mathrm{o}$ estabelecimento das conclusões. Sendo assim, durante a realização desse procedimento adotou-se algumas técnicas: classificação e categorização e, essencialmente, a análise de conteúdo.

$\mathrm{Na}$ visão de Silverman (2009), a análise do conteúdo é um método aceito de investigação textual e por isso pode ser utilizado por diferentes modelos de coleta. Existem várias formas de se analisar o conteúdo, contudo é importante verificar, inicialmente, o que se quer com as questões.

Uma boa análise de conteúdo não deve limitar-se à descrição. É importante que procure ir além, atingir uma compreensão mais aprofundada do conteúdo das mensagens através da inferência e da interpretação.

Para tanto, foi preciso que se criassem categorias de análise. As categorias representam possíveis respostas para sua pergunta e essas categorias podem ser criadas através dos dados coletados, ou podem ser pré-estabelecidas. $\mathrm{O}$ quadro 1 a seguir, apresenta o conjunto de categorias de análise necessários para este estudo.

Quadro 1: Categorias de análise

\begin{tabular}{|c|c|c|}
\hline BASE TEÓRICA & CATEGORIAS DE ANÁLISE & AUTORES CENTRAIS \\
\hline $\begin{array}{l}\text { Gestão Eletrônica de Documentos } \\
\text { (GED) }\end{array}$ & $\begin{array}{l}\text { 1) Recebimento e preparação de } \\
\text { documentos. } \\
\text { 2) Geração de capa de lotes. } \\
\text { 3) Digitalização e inspeção de } \\
\text { documentos. } \\
\text { 4) Indexação de documentos. } \\
5 \text { Compactação de imagens. } \\
\text { 6) Auditoria, confirmação, } \\
\text { armazenamento e cópia de } \\
\text { contratos } \\
\text { 7) Envelopamento de faturas. } \\
\text { 8) Controle de qualidade. }\end{array}$ & $\begin{array}{l}\text { Ágora (2012) } \\
\text { Silva (2003) }\end{array}$ \\
\hline
\end{tabular}

Fonte: elaborado pelos autores
Dessa forma, entendeu-se que as categorias de análise estabelecidas permitiram identificar informações complementares sobre diferentes aspectos estudados quanto às características da gestão eletrônica de documentos.

A seguir será apresentada a Cooperativa onde foi realizado o estudo, bem como serão descritos todos os aspectos necessários para poder compreender como se dá a gestão eletrônica de documentos.

\section{Análise dos Resultados}

\subsection{A Cooperativa de Assistência à Saúde - Unimed Santa Maria}

Sua fundação data de 13 de julho de 1972 e ocorreu após uma reunião em assembleia geral entre 70 médicos da Sociedade de Medicina de Santa Maria e da Sociedade de Medicina do Médio Jacuí, que juntos ofereceram aos moradores da cidade de Santa Maria e região, um atendimento com melhor qualidade na área da saúde, melhor acesso e produção para os médicos conveniados, sendo que o primeiro presidente da Unimed Santa Maria permaneceu no cargo durante 17 anos.

A Cooperativa Unimed Santa Maria possui em funcionamento 10 escritórios regionais nas cidades de Agudo, Faxinal do Soturno, Jaguari, Restinga Seca, Santiago, São Francisco de Assis, São Gabriel, São Pedro do Sul, São Sepé e São Vicente do Sul, abrangendo uma área de 28 municípios da região central do estado.

A Unimed Santa Maria é uma cooperativa de trabalho médico e oferece planos de atendimento à saúde em diversas modalidades, Individuais e Familiares, Empresariais e por Adesão e na área de Saúde Ocupacional. Possui estrutura física adequada aos atendimentos, hospital próprio, atendimento de Medicina Preventiva às empresas conveniadas, Atendimento Domiciliar, SOS Unimed e Serviço de Medicina do Trabalho contando com uma equipe de profissionais médicos e funcionários extremamente qualificada.

Tem como Missão "Promover a Assistência Integral à saúde, oferecendo produtos e serviços de qualidade a maior parcela da população, gerando a satisfação de todos envolvidos”.

São Objetivos da Unimed: "Aos cooperados: Proporcionar trabalho médico com remuneração digna, crescimento profissional e integração, 
comprometendo a todos com os resultados. Aos colaboradores: Promover seu comprometimento, assegurar um clima organizacional saudável, valorizar e estimular seu crescimento profissional com remuneração digna. Usuários: superar suas expectativas, comprometendo-os com suas obrigações. Aos Fornecedores: Promover parcerias sólidas e confiáveis de mútuos benefícios. Comunidade: Integrar-se, desenvolvendo ações de saúde preventivas, educativas e sociais".

Situada a Rua Professor Braga, número 141, Santa Maria, compõe uma estrutura física em área central e sua forma como empresa organizada é composta por diversos profissionais qualificados e funcionários comprometidos favorece aos beneficiários, clientes, fornecedores, associados e colaboradores o máximo em atendimento conforto e prestação de serviços à comunidade santa-mariense e de regiões próximas. Atualmente, a cooperativa Unimed conta com 781 médicos associados exercendo suas atividades nas diversas especialidades médicas e com aproximadamente 45.429 beneficiários credenciados a planos assistenciais e 2.346 beneficiários cadastrados no plano FATES.

A sede da Cooperativa, Unimed Santa Maria, conta com 13 estagiários que prestam serviços a organização contribuindo com $\mathrm{o}$ crescimento profissional dos estudantes e agilizando juntamente com os funcionários, os processos internos da cooperativa.

Por fim, o quadro de colaboradores na sede administrativa é composto de 138 funcionários, sendo que o número total de colaboradores na Unimed Santa Maria, somando-se a Sede, Hospital, Medicina Preventiva, SOS, Atendimento Domiciliar e Serviço de Medicina Ocupacional totalizam-se em 573.

\subsection{A gestão eletrônica de documentos (GED) na Unimed Santa Maria}

O processo de Gestão Eletrônica de Documentos (GED) possui uma série de atividades interrelacionadas, a fim de atender as necessidades e demandas "não exclusivas", porém predominantes de Contratos, movimentação de usuários e Contas Médicas.

Conforme um dos entrevistados,

a GED é o processo que compreende uso da tecnologia tornando as informações físicas salvaguardadas eletronicamente sob a seguridade permanente da organização ao passo que possibilita a empresa organizar, controlar e caso haja necessidade recuperar documentos.

Ademais, segundo o entendimento de outro entrevistado,

a GED é uma nova maneira utilizada para o manuseio de documentos, gerenciando-os desde o recebimento até o descarte. Essa ferramenta engloba inúmeras diretrizes, quesitos, procedimentos para armazenamento e arquivamento. Desta maneira entende-se que a gestão eletrônica de documentos é a compactação e a evolução dos procedimentos administrativos.

Em se tratando da importância da GED na tomada de decisão da cooperativa, os profissionais enfatizam a agilidade, a praticidade e a facilidade no acesso, uma vez que os documentos digitalizados ficam armazenados no diretório central da empresa, e o acesso ao sistema pode ser feito de qualquer computador, possibilitando o acesso para os gestores e também para os colaboradores. Isso pode ser observado no relato a seguir.

O GED fornece subsídios de apoio à tomada de decisão, através da agilidade da disponibilização das informações, ao passo que o tomador de decisão encontrará na tela de seu computador os recursos informativos sem a necessidade de acesso aos sistemas arquivísticos tradicionais ou sem os riscos de não encontrar a documentação que deseja.

A GED é aplicada no setor específico de faturamento da Unimed Santa Maria e utiliza os seguintes documentos como referência para sua aplicação na cooperativa: documentos e relatórios fornecidos pela Unimed Central RS (SICADIN e outros); apresentações e relatórios fornecidos em oportunidades de treinamentos e worshops ministrados pela equipe de Gestão Eletrônica de Documentos de Canoas/RS.

Por conseguinte, é importante destacar as abreviaturas e definições descritas no POP:

- Bandejas: são repositórios temporários os quais possibilitam a indexação dos documentos, codificando-os e os enviando para o data center.

- Capa de lote: identificação impressa, cuja função nomeia o documento a ser processado.

- Documentos correntes: são documentos novos, os quais são processados no momento em que chegam.

- Docuware: programa cuja responsabilidade corresponde ao armazenamento dos documentos devidamente escaneados, indexados e revisados. 
- GED: gestão eletrônica de documentos.

- Guias: documento de autorização grado pelo setor de autorizações.

- Guias tipo 1: consultas.

- Guias tipo 2: procedimentos ambulatoriais.

- Guias tipo 3: internação.

- Guias tipo 4: gastos (engloba toda a conta, é marcada como guia principal, com exceção dos pacotes).

- Indexação: codificação manual apresentada por uma numeração, a qual possibilita o armazenamento, procura e exclusão de documentos.

- KODAK capture pro software: programa que possibilita que as imagens digitalizadas sejam "tratadas" (retira borrões e exclui páginas indesejadas e ajusta), é composto por uma série de ferramentas capazes de corrigir deformidades nos documentos, possui opções de seleção para cada tipo de documento com as seguintes opções: Contratos, Sicadin e PDF. (A opção Sicadin remeterá a documentos contras médicas).

- Documentos legados: são documentos já armazenados sem passar pelo processo de GED, cuja intenção pressupõe o seu processamento.

- Pacotes: são documentos os quais discriminam os gastos de materiais e medicamentos, o qual se encontra em anexo para melhor entendimento.

- PEA: plano de extensão assistencial.

- PROs: são procedimentos, normas produzidas pela equipe da Unimed Central RS e sua equipe de GED, estão acondicionadas ao acesso de todos os usuários do programa Docuware, o qual possui recomendações sobre o processo de GED de cada documento.

- TAG: são folhas de frente e verso em branco, cuja função destina-se a separar um documento do outro no scanner, como por exemplo, um contrato de outro contrato;

Ademais, os 06 (seis) profissionais que atuam no setor de faturamento da Cooperativa exercem diferentes funções em diferentes cargos:

- Auxiliar administrativo: realiza a preparação de documentos (retirada de grampos, descarte de segundas vias para documentos: Contas médicas), destaque e ordenação de contratos quanto à utilização da ferramenta TAG de separação, disponibilização de pré-existências (digitalização, indexação das declarações de saúde), confecção de etiquetas autoadesivas e organização de contratos para armazenamento, remontagem de contas com grampos plásticos estendidos.

- Auxiliar administrativo: realiza preparação, tratamento e indexação de documentos, atendimento as demandas internas e externas, procura de documentos na plataforma de armazenamento da Central RS, organiza o acervo de documentos no sistema arquivístico de contratos. Colabora com o fechamento de faturas e manutenção da envelopadora.

- Auxiliar administrativo: realiza a digitalização e disponibilização de pré-existências, confecção de capas de lote, montagem e remontagem de contas, separação de obrigatório e não obrigatórios, procedimento de etiquetamento e organização do acervo, preparação de contratos, responsável pela realização do fechamento de faturas (faturamento e cobrança) realiza manutenção periódica da envelopadora e mantem contato com responsáveis terceiros pela manutenção da máquina referida.

- Assistente administrativo: realiza a confecção de capas de lote, montagem e remontagem de contas, separação de obrigatório e não obrigatórios, disponibilização das contas nos nichos, colabora com a preparação de documentos em geral e na atividade de etiquetamento e armazenamento de contratos.

- Analista administrativo: realiza o processamento dos documentos quanto a tratamento, indexação, atendimento as demandas internas e externas, procura de documentos na plataforma de armazenamento da Central RS, colabora na organização e adaptação dos sistemas arquivísticos junto às normas do CONARQ (conselho Nacional de Arquivos) mantem contato profícuo e periódico com a equipe de TI da Central RS, bem como equipe de GED em Canoas.

- Gerente geral: responsável por toda a manutenção da engrenagem que garante o andamento correto das funções de apoio. Atua com a gestão da equipe, respondendo pelos recursos humanos, supervisionando o setor de faturamento dando assessoria a presidência da cooperativa, conduzindo reuniões de recursos materiais e financeiros do setor providenciando meios para que as atividades sejam desenvolvidas em conformidade com as normas e procedimentos técnicos.

Com base nestas considerações e, conforme as entrevistas, a análise documental e a observação direta, serão apresentadas na sequência as etapas que a Unimed realizada na medida em que desenvolve a gestão eletrônica de documentos. 


\subsubsection{Recebimento e preparação de documento}

O recebimento de documentos é a primeira etapa do processo. Os documentos "contratos" são recebidos do setor de cadastro e os documentos "Contas Médicas" são recebidos do setor de faturamento. Assim dispostas em cestas, as quais seguem requisitos ordeiros de manuseio: contas nacionais, estaduais Porto Alegre, estaduais federação e estaduais diversas. Posteriormente ao recebimento, inicia-se a atividade de preparação.

$\mathrm{Na}$ preparação de documentos é realizada a retirada de grampos, clips e outros materiais para não causar avarias no scanner, seguindo assim, as especificidades de cada documento que se segue: Contratos: destaca-se folha a folha dos contratos, após se faz a montagem separando com a ferramenta TAG cada documento específico do contrato.

Posterior a isso, é então montado um lote de contratos. No entanto, a preparação dos documentos "Contas Médicas" pressupõe a seguinte sequencia: Retirada de grampos e clips, retirada de segundas vias, carbonos e ordenação dos documentos principais à frente, para tanto, os documentos impressos em meia folha são organizados conforme anexo, para assim dar sequência na geração de capas de lote.

$\mathrm{Na}$ visão de um dos entrevistados,

o processo inicia-se com o recebimento de protocolo informando o lote, tipo, e quantidade documentos, após a preparação dos documentos executando a retirada de grampos, clipes, separando por tipo; exemplificando no caso de um contrato separasse por tipo e código os documentos, cadastro, contratos, documentos pessoais e planilhas, após faz a montagem do documento para digitalização.

Segundo outro entrevistado,

o recebimento consiste na verificação criteriosa da documentação física e em relatórios cuja finalidade compreende a certificação inicial do processo. A preparação consiste na classificação, ordenação e retirada de excessos, é a atividade que realiza a retirada de grampos e zela pela integridade da documentação antes da digitalização.

Dessa forma, o processo de recebimento e preparação de documento na GED se faz necessário, pois a retirada de "clips", grampos, colas ou qualquer elemento que prejudique sua passagem no scanner é indispensável para obter uma organização eficaz dos documentos, em uma sequência definida que não prejudique a posterior digitalização dos mesmos. Observando o que é realizado na Unimed, verificou- se que este conjunto de procedimentos é bastante semelhante ao que propõem Ágora (2012) e Silva (2003).

\subsubsection{Geração de capas de lote}

A geração de capas de lote é uma atividade que se restringe exclusivamente a documentos "Contas Médicas". Por primeiro, é verificada a guia principal da conta e se a mesma possui PEA (Programa de Extensão Assistencial). Posteriormente entra-se no programa SAS-Sputnik onde é passada no leitor óptico o código de barras que contém a guia principal.

Caso não haja codificação, digita-se o código da guia principal da conta, colocando a numeração a ser indexada a qual possui o número do usuário e número da Nota. Dessa forma é visualizado o nome do usuário para melhor conferência comparativa. Caso haja PEA, deve ser sinalizada (clicada) no botão PEA.

Dando sequência, é impressa a capa de lote com código de barras, e colocada à frente da conta. Mediante tais procedimentos, segue algumas recomendações: quando o pacote não estiver vinculado à guia principal, deve-se então gerar uma capa de lote separada, independente da vinculação, deve-se sempre gerar uma capa para o pacote, posterior a isso, o profissional responsável coloca nos nichos (estanterias) um lote de contas à disposição para digitalização.

Diante destas considerações, a geração de capa de lote é um documento importante, pois o mesmo possibilita o controle e proporciona a devida agilidade para liberação de informações do procedimento realizado pelo usuário.

\subsubsection{Digitalização e inspeção de documentos}

A digitalização de contas médicas pressupõe as seguintes etapas: Retirada dos documentos dos nichos (estanterias) colocando-os no scanner, utilização do software: KODAK Capture Pro Software o qual possibilita que as imagens digitalizadas sejam "tratadas" (retirada de borrões e exclusão de páginas indesejadas e ajustamento das mesmas).

Após, inicia-se a digitalização da capa de lote que possui um código de barras na qual realiza a indexação de maneira automatizada. Posterior a isso, são remontadas as contas e colocadas nas cestas deixando-as ordenadamente à disposição do setor de faturamento. 
Os documentos são enviados para dois destinos, o primeiro é para o programa SICADIM onde são capturados pelo setor de faturamento, e o segundo, são armazenados no Data Center da Unimed Central RS e podem ser baixados a qualquer momento.

Já a digitalização de contratos pressupõe as seguintes etapas: retirada dos lotes de contratos nos nichos (estanterias), colocando-os no scanner, utilização do software: KODAK Capture Pro Software o qual possibilita que as imagens digitalizadas sejam "tratadas" (retirada de borrões e exclusão de páginas indesejadas e ajustamento das mesmas). Posterior a esta etapa são gerados os lotes e enviados para a bandeja para então serem indexados manualmente.

De acordo com o depoimento de um dos entrevistados, a digitalização "compreende a inserção dos documentos já preparados no scanner, a fim de torná-los digitais". Outro entrevistado manifestou que "essa atividade possibilita a visualização dos documentos e tratamento (retirada de borrões ou imperfeições) por meio de um software". Por fim, um terceiro entrevistado apontou que "a inspeção ocorre durante todas as atividades inerentes ao processo, desde a preparação, digitalização, tratamento, indexação e posterior ao armazenamento".

Dessa forma, a digitalização é importante dentre as etapas da GED, pois a mesma possibilita a visualização do documento em forma digital, proporcionando uma posterior pesquisa de forma rápida, objetiva e eficaz.

\subsubsection{Indexação de documentos}

A fase de indexação de contratos é realizada a codificação dos documentos com base nas seguintes tipologias

\section{Figura 3: Tipologias}

$\begin{array}{ll}1 & \text { Contrato de Assistência à Saúde de Pessoas Físicas e Jurídicas em Vigor } \\ 2 & \text { Contrato de Assistência à Saúde de Pessoas Físicas e Jurídicas Rescindidos } \\ 3 & \text { Comprovantes de identifícação (Ficha CNPJ, RG.CPF, etc). } \\ 6 & \text { Declaracãa de Saúde em Contratos em Vigor } \\ 7 & \text { Declaração de Saúde em Contratos Rescindidos } \\ 12 & \text { Movimentação de Beneficiários de Contratos em Vigor } \\ 13 & \text { Movimentação de Beneficiários de Contratos Rescindidos } \\ 18 & \text { Outros Documentos }\end{array}$

Fonte: GED, Unimed Santa Maria (2013)

Posteriormente são colocadas a numeração do contratante, contrato e data e então são enviados ao data center, encerrando assim a atividade de indexação de contratos.

De uma forma sucinta, alguns entrevistados definem essa etapa da seguinte forma: "Nesta etapa efetua-se a busca no diretório de arquivos para indexar, após, efetua-se o cadastramento dos arquivos (imagens) seguindo as especificações de cada tipo de documento e, logo, envia para o arquivo central da empresa". "Caracteriza-se pelo preenchimento da codificação e da nomeação que define as especificidades da documentação subsidiada por procedimentos que norteiam a produção eletrônica compilada por membros das Unimeds singulares a fim de padronizar o processo de GED. É por meio da indexação que se torna possível a procura e a disponibilização de documentos eletrônicos."

Sendo assim, a indexação é uma atividade muito importante no processo da GED, pois a mesma inclui rotinas e procedimentos específicos que possibilitam maior eficiência e agilidade no gerenciamento e controle das informações, identificando a tipologia documental e criando um plano de classificação.

\subsubsection{Compactação de imagens}

É um procedimento automático que comprime as imagens em formato tiff possibilitando o tráfego de informações de forma mais ágil. Também é possível realizar a compactação mediante o acesso web client baixando as informações em formato $p d f$.

Diante disso, a compactação de imagens é um fator importantíssimo no processo da GED, possibilitando uma redução do peso da imagem otimizando a velocidade de carregamento da página da web pelo usuário.

\subsubsection{Auditoria, confirmação, armazenamento e cópia de contratos}

$\mathrm{Na}$ auditoria e confirmação de contratos é realizada a verificação e análise da documentação se essa corresponde com a numeração indexada e a comparação do digitalizado com o físico, caso haja algum erro é efetuada a correção no momento, se não haver ratificações é confirmada a operação no programa GED.

O armazenamento de contratos precede as seguintes ações: Retirada dos lotes de contratos já confirmados, são retirados os documentos fotocopiados (RG, CPF, comprovantes de residência, 
vínculos empregatícios, certidões de nascimento) colocando-os nas respectivas capas e grampeando-os.

É realizada a confecção de etiquetas adesivas com o número do contratante e colocadas em envelopes pardos sem timbre, então, são envelopados e armazenados no arquivo em caixas numeradas, recomenda-se colocar no máximo 25 contratos em cada caixa.

Para atender as solicitações de cópias de contratos, primeiramente, são verificados no sistema a existência do mesmo, caso não haja, o contrato original é procurado no arquivo físico e realizadas as etapas conforme as pressuposições de preparação, digitalização, indexação e confirmação.

Em suma, a auditoria e a confirmação de contratos identificam-se como instrumentos indispensáveis entre as melhores práticas organizacionais, pois os mesmos possibilitam a apuração de possíveis erros, o aperfeiçoamento e a garantia da qualidade do contrato estabelecido.

\subsubsection{Envelopamento de faturas}

Essa etapa precede o fechamento de faturas de pessoa física e jurídica, de cobrança e eventuais documentos que necessitam de envelopamento. Para o envelopamento é utilizada a máquina de envelopar.

Inicialmente é realizada a verificação da máquina quanto à limpeza de cola e as regulagens. Logo, coloca-se a cola em um recipiente da máquina e posteriormente colocam-se folhas rascunhos para teste de colagem, picote e dobradura.

Caso esteja ocorrendo bem, inicia-se o procedimento colocando as faturas em lotes de 100 . Nesta atividade é possível que haja avarias nas faturas (deteriorar, amassar, rasgar) bem como envelopes descolados.

Caso aconteçam esses danos, as faturas são entregues ao setor responsável para a geração de novas faturas, e o envelopamento é realizado manualmente. Encerrado esta atividade, as faturas são colocadas em caixas e entregues ao setor de expedição. Realizada esta etapa, é então feita a limpeza na máquina retirando a cola e lavando as peças. São envelopadas em média 13.000 faturas mensais.

Diante do exposto, é de vital importância o envelopamento das faturas para manter a privacidade e o sigilo dos dados do usuário.

\subsubsection{Controle de qualidade}

Conforme declara a Gerente Geral da cooperativa, "todo o processo, via de regra, deve obrigatoriamente atender esse preceito, desde a origem ou entrada (recebimento) até as saídas (armazenamento) ".

As falas de outros entrevistados confirmam estas ideias. "O controle ocorre no processo de preparação, como por exemplo, tirar folhas amassadas, grampos e excesso de folha, bem como no tratamento, onde é feita a retirada de riscos da imagem até a montagem final do papel, cuidando a simetria". Outro afirma "este preceito ocorre desde o primeiro contato com os documentos, no recebimento, na preparação, pois, caso haja alguma não conformidade o mesmo é devolvido á origem, na digitalização, durante a indexação e armazenamento e por fim durante a auditoria". Por fim, outro confirma "o controle de qualidade ocorre através de etapas que ocorrem durante o processo, ou seja, na preparação, na digitalização na indexação e posteriormente confirma-se com a auditoria do trabalha efetuado".

Assim, é notório que o controle de qualidade é imprescindível em todo o processo da GED. Através dele é possível diminuir e reconhecer os erros em busca de um padrão de excelência.

\subsubsection{Outros}

Em termos de outros procedimentos necessários ao GED, verificou-se que a digitalização de preexistência e o processamento dos documentos obrigatórios de contas Médicas são também necessários para o desenvolvimento da mesma. Em suma, a Digitalização de Preexistência, inicia-se com o seu recebimento do setor de cadastro, após, elas são digitalizadas e posteriormente são disponibilizadas. Assim, inicia-se as colocando no scanner de mesa e digitalizando as três laudas, após, nomeia-se com o nome do promitente da declaração e é armazenado na pasta "declaração de saúde", após utiliza-se o software declaração de saúde, procura-se o nome e então é feito o anexo do documento, logo, nomina se novamente com o promitente, coloca-se a data e nome do médico perito e envia-se.

Por sua vez, no processamento dos documentos "obrigatórios" de contas Médicas, são recebidas as contas com estes documentos separados, então, precede o processo de preparação e geração de capas de lote, coloca-se no scanner e realiza-se o processo 
de tratamento, posterior a geração dos lotes de documentos realiza-se a captura na pasta AIBACKUP.001 por intermédio do software FastStone Image Viewer, o qual possibilita a exclusão de documentos não obrigatórios.

\subsubsection{Considerações do estudo}

Além destas questões, considerou-se relevante avaliar se os entrevistados conhecem os modelos teóricos deste estudo e analisar sua relação com a gestão eletrônica de documentos da Unimed.

Através das declarações dos profissionais entrevistados, foi observado que a maioria dos mesmos desconhece modelos científicos ou referenciais teóricos que apresentam as etapas do sistema operacional GED. Foi constatada a utilização de uma adaptação do modelo de processo utilizado pela Unimed Central de serviços RS, conforme expresso no relato de alguns profissionais.

Desconheço os modelos científicos que abordam o processo (GED). Os subsídios teóricos ficam a cargo da Unimed Central de Serviços RS, a qual norteia e inter-relaciona as demandas que envolvem gestão eletrônica de documentos do Sistema Unimed Central RS e da Unimed Santa Maria RS promovendo eventos anuais para discussão de novas práticas e amparo legal para a aplicação do GED.

Os subsídios acadêmicos, tecnológicos e estruturais são compilados de maneira conjunta entre a Unimed Central de Serviços RS e a equipe de profissionais de GED e de setores correlatos da Unimed Santa Maria com stakeholders e parceiros desde a área jurídica, gestores e prestadores, amplamente discutido em eventos anuais em modelos de palestras e workshops.

Apesar de os profissionais desconhecerem os referenciais teóricos que norteiam o estudo, ficou evidente através dos relatos, a correlação entre as etapas descritas por Ágora (2012) e Silva (2003) e as etapas complementares aplicadas pela Unimed Central RS.

Assim, foi verificado que o procedimento da GED na Unimed Santa Maria corrobora com as etapas descritas pelos autores norteadores do estudo, conforme a expressão a seguir: "As etapas da GED na cooperativa são as seguintes: recebimento e preparação dos documentos, digitalização, indexação, armazenagem e auditoria e controle de qualidade".

A fala de outro entrevistado confirma esta ideia, "nós trabalhamos com as seguintes etapas na GED: recebimento de documento, preparação de documentos, criação de capa de lote, digitalização, indexação, compactação, auditoria de contratos e encaminhamentos necessários (controle de qualidade)".

Diante do exposto, ficou evidente que os autores condutores desse estudo foram esclarecedores na apresentação das etapas operacionais da GED. Através da disponibilização de informações oportunas, Ágora (2012) e Silva (2003) enriqueceram e acrescentaram o estudo. Foi possível entender a importância da Gestão Eletrônica de Documentos em uma cooperativa como suporte à gestão, armazenamento e recuperação documental.

\section{Conclusão}

Este trabalho justificou-se por apresentar um tema de grande interesse para as Cooperativas, dada a importância da questão tecnológica e da informação. Por isso a importância de buscar sempre incentivar as organizações a implementar novas técnicas como a GED, que agrega inúmeras vantagens com excelente relação custo/benefício, agilidade e eficiência.

Por isso, o presente estudo teve por objetivo principal identificar e compreender o funcionamento da Gestão Eletrônica de Documentos (GED) em uma cooperativa do ramo da saúde, da região Central do Rio Grande do Sul. Para isso, foi realizada uma observação do funcionamento da GED durante o período dedicado ao estágio, procurando relacionar os conceitos formulados à sua aplicação na prática, participando do dia a dia da organização, bem como desempenhando funções, trabalhando com a GED. Além disso, indagou-se aos respectivos funcionários sobre o conhecimento de todo o processo que compreende uso da tecnologia GED, bem como se realizou uma análise documental contextualizando as etapas da GED aplicadas na cooperativa com as fases da GED descritas no referencial teórico abordado neste estudo.

A partir do estudo realizado observou-se a importância da GED para minimizar a troca de documentos via malotes ou similares entre a matriz e suas filiadas, trazendo assim melhorias nos processos operacionais, ganhando economia de espaço físico e ainda oportunizando a redução de custos com impressões.

Com a investigação realizada foi possível ampliar os conhecimentos no que tange à gestão eletrônica de documentos e suas funcionalidades na cooperativa. 
Entretanto, evidenciou-se também o pouco conhecimento do grupo entrevistado sobre os modelos científicos ou referenciais teóricos que apresentam as etapas do sistema operacional GED. Os mesmos constataram a utilização de uma adaptação do modelo de processo utilizado pela Unimed Central de serviços RS, para a aplicação do GED na Unimed Santa Maria RS.

Apesar de os profissionais desconhecerem os referenciais teóricos que norteiam o estudo, ficou evidente através dos relatos, a correlação entre as etapas descritas por Ágora (2012) e Silva (2003) e as etapas complementares aplicadas pela Unimed Central RS.

Dessa forma, foi verificado que o procedimento da GED na Unimed Santa Maria corrobora com as etapas descritas pelos autores norteadores do estudo.

Sendo assim, existe uma real necessidade de conhecimento sobre referenciais bibliográficos que abrangem o tema proposto, para permitir a formação de uma base de conhecimentos necessários para a melhor compreensão e aplicação da GED na Unimed Santa Maria, RS.

Para promover esse conhecimento sugere-se que haja uma implementação de grupo de estudos e pesquisas na área da Gestão Eletrônica de Documentos, direcionado aos funcionários que operam diretamente com a a GED. É de vital importância a realização de pesquisas bibliográficas em busca de um apanhado sobre as principais literaturas e trabalhos científicos realizados sobre o GED atualmente. Isso pode contribuir gradativamente, para o desenvolvimento da cooperativa ao passo que o crescimento pessoal e individual dos funcionários influencia diretamente no crescimento da própria Unimed Santa Maria/RS.

\section{Referências}

\section{ALECRIM, E. O que é tecnologia de informação} (TI)?, 2011. Disponível em: <http://www.infowester.com/ti > Acesso em: 20 mai 2016.

ÁGORA. P. Gerenciamento eletrônico de documentos (GED): aplicação na Universidade Federal de Santa Catarina. Florianópolis, v. 22, n. 45, 2012.
BALDAM, R. L. GED: gerenciamento eletrônico de documentos. São Paulo: Érica, 2002.

BEAL, A. O sistema de informação como estratégia empresarial. São Paulo: Atlas, 2009.

BETTIS, R. A.; HITT, M. A. The new competitive landscape. Strategic Management Journal. v. 16, n. 4, 1995.

BRASIL. Lei Federal $\mathbf{n}^{\mathbf{0}}$ 8.159, de 08 de janeiro de 1991. Dispõe sobre a política nacional de arquivos públicos e privados e dá outras providências. Diário Oficial da República Federativa do Brasil. Brasília, 1992.

CAMPOS FILHO, M. P. Os sistemas de informação e as modernas tendências da tecnologia e dos negócios. Revista de Administração de Empresas, v. 34, n. 6, 1994.

CARVALHO, W. Gestão participativa na SEMCO equipamentos: implantação e consolidação. 2010. 98f. Dissertação (Mestrado Profissional em Administração) - Fundação Cultural Dr. Pedro Leopoldo. Faculdades Integradas de Pedro Leopoldo. Pedro Leopoldo, 2010.

GEDNET. Gestão eletrônica de documentos. 2016. Disponível em: 〈http://www.ged.net.br > Acesso em: 10 mar 2016.

GIL, A. C. Como elaborar projetos de pesquisa. São Paulo: Atlas, 1996.

GOLDENBERG, M. A arte de pesquisar: como fazer pesquisa qualitativa em ciências sociais. Rio de Janeiro: Record. 2007.

HOLYOLAKE, G. J. Historia de los pioneiros de rochdale. Buenos Aires: Intercoop, 1989.

LAKATOS, E. M.; MARCONI, M. A. Fundamentos metodologia científica. São Paulo: Atlas, 2001.

LIMA, N. C. Gestão eletrônica de documentos (GED) em cooperativas de crédito: um estudo de caso. 2013. Trabalho de Conclusão de Curso, Universidade Estadual da Paraíba, 2013. 
MENDES, M. M.; PASSADOR, C. S. Educação cooperativista, participação e satisfação dos cooperados: verdades incertas. In: I Encontro brasileiro de pesquisadores em cooperativismo, 2010, Brasília. Anais eletrônicos do Observatório do Cooperativismo. Ribeirão Preto: FEA-RP/USP, 2010. Disponível em: http://www.fearp.usp.br/cooperativismo/18.pdf. Acesso em: 15 abr 2016.

MENEZES, J. S. Mercado cooperativista: a influência do cooperativismo para o desenvolvimento da sociedade. Revista Jurídica Consulex, v. 12, n. 3, 2012.

MINAYO, M. C. S. O desafio do conhecimento: pesquisa qualitativa em saúde. São Paulo: Hucitec, 2004.

MOREIRA, S. V. Análise documental como método e como técnica. In: DUARTE, J; BARROS, A (Org.). Métodos e Técnicas de pesquisa em comunicação. São Paulo: Atlas, 2005.

MORENO, N. A. Gestão documental ou gestão de documentos: trajetória histórica. Londrina: Eduel, 2008.

\section{ORGANIZAÇÃO DAS COOPERATIVAS} BRASILEIRAS. Organização das Cooperativas Brasileiras, 2004. Disponível em:<www.ocb.com.br> Acesso em: 18 mar 2016.

—. Geração Cooperação - 2008. Disponível em: < www.geracaocooperacao.com> Acesso em: 18 abr 2016.

Cooperativismo - 2014. Disponível em: 〈www.brasilcooperativo.coop.br> Acesso em: 18 abr 2016.

QUIVY, R.; CAMENHOUDT, L. V. Manual de investigação em ciências sociais. Lisboa: Gradiva, 2005.

SANTOS, C. C. M..; CEBAlloS, Z. H. M. A importância do cooperativismo. Revista Univap, v. 13, n. 24, 2006.

SANTOS, E. M.; ROQUETE, F. F. Práticas de gestão em cooperativas: um estudo de caso de uma cooperativa de transporte de passageiros em táxi de Belo Horizonte. X Simpósio de Excelência em Gestão e Tecnologia. Resende, Rio de Janeiro, 2013.

SANTOS, V. B. Gestão de documentos eletrônicos: uma visão arquivística. Brasilia: ABARQ, 2005.

SCHENDEL, D. Technological transformation and the new competitive landscape. Strategic Management Journal, v. 16, n. 4, 1995.

SILVA, D. P. Gerenciamento eletrônico de documentos: a tecnologia que está mudando o mundo. Faculdade de Administração e Informática, $2004 . \quad$ Disponível em: <http://www.curitiba.arquivar.com.br/espaco_profissi onal/sala_leitura>. Acesso em: 7 abr 2016.

SILVERMAN, D. Interpretação de dados qualitativos. Porto Alegre: Artmed, 2009.

STAKE. R. E. Case studies. In: DENZIN, N. K.; LINCOLN, Y. S. (ed.) Handbook of qualitative research. London: Sage, 2000.

STARBIRD, R. W.; VILHAUER, G. C. Como tomar a decisão de implantar a tecnologia do gerenciamento eletrônico de documentos: tudo o que você precisa saber para decidir corretamente. São Paulo: CENADEM, 1997.

TAPSCOTT, D. The digital economy: promise and peril in the age of networked intelligence. New York: McGraw-Hill, 1995.

TIAGO, J.; REIS, L. Arquivologia facilitada: teoria e questões comentadas. Rio de Janeiro: Elsevier, 2011.

WERLICH, F. O mercado de GED e o papel do bibliotecário nas empresas de GED no Brasil. Florianópolis. UDESC, 2007. Disponível em: <http://www.pergamum.udesc.br/dadosbu/000000/00 0000000006/000006F2.pdf>. Acesso em: 03 abr 2016. 